\title{
Molecular Characterisation of DNA of Brown Plant Hopper Biotypes (Nilaparvata lugens L.) Under Screening Study of Brown Plant Hopper Resistance in Various Rice Genotypes at Gangavathi
}

\author{
Farzana Korabu*, B. Kisan, I. Shanker Goud, Ayyangowda Patil, \\ Mahantesh Shivyoggaya and Sujay Hurali
}
Department of Genetics and Plant Breeding, College of Agriculture, Raichur University of Agricultural Sciences, Raichur-584101, Karnataka, India

*Corresponding author

\section{A B S T R A C T}

The Brown plant Hopper (BPH) Nilaparvata lugens L. (Homoptera: Delphacidae) is one of the most destructive insect pests causing significant yield loss in most of the rice cultivars of India as well as Asia.it is a typical

\begin{tabular}{|l|}
\hline Ke y w o r d s \\
BPH, Primers, \\
SSR markers \\
\hline Article Info \\
\hline Accepted: \\
20 June 2020 \\
Available Online: \\
10 July 2020 \\
\hline
\end{tabular}
phloem feeder. Hence, present study was undertaken on DNA molecular characterization of BPH population using SSR markers that will give clear understanding of BPH diversity in Gangavathi region. Ten SSR markers were screened in the selected 25 BPHs and all ten markers were screened to assess the molecular diversity.Genotyping data of SSR markers were analyzed using Unweight pair group method with Arithmetic Mean (UPGMA) method using DARwin V6.0. This analysis clustered $25 \mathrm{BPH}$ populations into three groups. Cluster-I had highest number of BPH possessing $21 \mathrm{BPH}$ population. Cluster-II with three BPH and cluster-III had one solitary BPH population. This indicates that majority of the BPH populations are similar at Gangavathi whereas two biotypes are quite different.

\section{Introduction}

More than 90 per cent of the world's rice is grown and consumed in Asia where 60 per cent of the global population lives. Approximately 52 per cent of the global production of rice is lost annually owing to the damage caused by biotic stress factors, of which 25 per cent is attributed to the attack of insect pests. Historically BPH was a minor pest of rice, emerged as a major pest in the tropical Asia during green revolution of the 1960s. In India, the first severe outbreak occurred in Kerala during 1973-74 destroying about 50,000 ha of rice. The severe outbreak of this pest was noticed during 2007 in parts 
of Cauvery command area in Karnataka and during 2008 in Haryana, Punjab and Delhi.

Rice is infested by more than hundred species of insects and about twenty of them are considered serious pests as they cause significant damage to rice crop. Among them Brown plant hopper (BPH), Nilaparvata lugens (Homoptera: Delphacidae) is one of the most destructive insect pests causing significant yield loss causing hopper burn symptoms and acting as a vector for many virus diseases such as grassy stunt and rugged stunt in most of the rice cultivars of India as well as Asia.

The extensive cultivation of resistant cultivar of rice leads to evolution of new biotypes that are able to overcome the host plant resistance. Four biotypes were identified based on host plant differentials. The objective of the present study was undertaken on DNA molecular characterization of $\mathrm{BPH}$ population using SSR markers that will give clear understanding of BPH diversity in Gangavathi region.

\section{Materials and Methods}

\section{Collection and DNA extraction of brown plant hoppers}

Brown Plant Hoppers were collected from ARS Gangavati, Koppal district, Karnataka rice ecosystem and stored in alcohol and later DNA was extracted from each individual using the standard protocol. DNA quality was assessed using agarose gel electrophoresis by running $200 \mathrm{ng}$ of DNA in $0.8 \%$ agarose. The genomic DNA was quantified using spectrophotometer both at $260 \mathrm{~nm}$ and $280 \mathrm{~nm}$ wavelengths. A pure sample of DNA shows the ratio of OD 260/280 as 1.8.The ratio less than 1.8 indicated contamination in the isolation either with phenol or with proteins. The values higher than this indicate the presence of RNA in the isolation. Normalization of the DNA concentration was done to bring all the DNA concentrations to a relatively equal level by appropriate dilutions for PCR reaction.

PCR for SSR markers was performed with the following amplification conditions as mention in the table 1.Agarose gel $(3.0 \%)$ electrophoresis was performed and gel was viewed under UV trans- illuminator and the DNA banding pattern was recorded directly.

\section{Selection of primers}

Primers for present investigation were selected based on previous workers data (Shilpakala et al., 2012) and these selected markers were linked to brown plant hopper biotypes. Ten simple sequence repeats (SSR) markers were selected and details of the primers were mentioned in the table 2 .

\section{Scoring of bands}

The amplified bands were scored for each SSR primer pairs based on the presence or absence of bands, generating a binary data matrix of 1 and 0 for each marker system. Both matrices were then analyzed using the NTSYS pc statistical package version 2.2. The data matrices were used to calculate genetic similarity based on Jacquard's similarity coefficients. Polymorphic information content (PIC) values were calculated for each SSR locus based on Anderson et al., (1993). Major allele frequency, gene diversity, polymorphism information content (PIC) values were determined using Power Marker Version 3.25 (Liu and Muse, 2005).

\section{Results and Discussion}

Ten SSR markers were screened across 25 brown plant hoppers to assess the molecular 
diversity. Number of alleles, highest frequency allele, gene diversity and Polymorphism Information Content (PIC) values by Power marker software Version 3.25 (Table 3).

The level of polymorphism among rice cultivars was evaluated by calculating allelic number and PIC values for each of the ten SSR loci evaluated. A total of 59 alleles were detected for 25 brown plant hoppers. The results revealed that all the primers showed distinct polymorphisms among the cultivars studied indicating the robust nature of microsatellites in revealing polymorphism. Among the polymorphic markers, four markers (BM45, BM75, NLGS1680 and NLGS1016) produced five alleles each, three markers (NLGS2021, NLGS928 and NLGS231) produced six alleles each and three markers (NLGS368, BM263, and NLGS 872) produced seven alleles each. The number of alleles per locus ranged from five to seven alleles with an average of 5.90 alleles across the 59 loci.

The brown plant hoppers frequency of most common allele at each locus ranged from $52.00 \%$ to $63.80 \%$ of the 59 alleles scored all of 59 were found to be polymorphic. Gene diversity for ten markers ranged from 46.58 $\%$ (BM75) to $49.89 \% \quad$ (BM263 and NLGS231), average of the markers for gene diversity was $48.74 \%$. The Amplicon size of all 25 brown plant hoppers for each marker alleles varied from 130-167bp by NLGS231 and 200-253 bp produced by NLGS928.

The studied primers have revealed distinct polyphormism and also allele number, major allele frequency and gene diversity, have shared wide range of variation this is the indication of presence of variation in the studied population of BPH. Similar results were obtained by Krupa et al., (2017).
Polymorphism information content (PIC) value is a reflection of allele diversity and frequency among varieties. PIC values ranged from 0.3353 to 0.3745 with an average of 0.3650. The highest PIC value 0.3745 was obtained for NLGS368, BM263 and NLGS231. PIC value revealed that NLGS368 was considered as best marker for 25 brown plant hoppers (Plate 3a to 3d).

PIC values in the present study have shared maximum values this is the indication of presence of higher polymorphism of the molecular markers. This result is in accordance with the studies of Krupa et. al. (2017) studied molecular diversity of five rice genotypes using SSR markers and results are similar to that of carried out in this research. Nishanth (2017) studied molecular diversity of 60 rice genotypes using SSR markers.

\section{Clustering analysis of 25 brown plant hoppers with SSR markers}

Genotyping data generated by screening diverse set of twenty five rice brown plant hoppers with ten SSR markers was subjected for estimation of Jacquard's similarity coefficient and construction of genetic similarity matrix using unweight pair group method (UPGMA) analysis was done by using NTSYS statistical package version 2.2.

A cluster analysis using UPGMA based on similarity coefficients was done to resolve the phylogenetic relationships among the different submergence rice germplasm lines considered for the present study.

The unweight pair group method (UPGMA) clustering system generated three genetic clusters with similarity coefficient 71.00 per cent. Cluster-I had highest number of genotypes possessing 21 genotypes. Cluster-II with three genotypes and cluster-III had solitary genotype; details were presented in Table 4. 
A cluster analysis using UPGMA based on similarity coefficients was done to resolve the phylogenetic relationships among the different resistant rice considered for the present study. The unweight pair group method (UPGMA) clustering system generated three genetic clusters with similarity coefficient 71.00 per cent.

The extensive cultivation of resistant rice cultivars leads to evolving into new biotypes of brown plant hopper that are able to overcome the host plant resistance. Presently four biotypes are identified based on host plant differentials and in India biotype-4 is present. Molecular characterization of populations will give clear understanding of BPH diversity. Totally 25 Brown Plant Hoppers were collected in the field at Gangavathi and molecular characterization of brown plant hopper was conducted by extracting DNA of collected populations and kept PCR with ten SSR markers. Polymorphism among the populations collected from various places was done using these markers. The markers were selected from UNKA (BPH) EST BLAST page.Primers for present investigation was selected based on previous workers data (Shilpakala et al., 2012) and these selected markers were linked to Brown Plant Hopper biotypes.

Table.1

\begin{tabular}{|l|c|c|c|}
\hline Stage & Temperature $\left(^{\circ} \mathrm{C}\right)$ & Time (min) & No. of cycles \\
\hline Initial denaturation & 95 & 5 & 1 \\
\hline Denaturation & 94 & 0.5 & 35 \\
\hline Primer annealing & 52 & 0.5 & \\
\hline Extension & 72 & 2 & \\
\hline Final Primer extension & 72 & 8 & 1 \\
\hline Hold & 4 & Till removal & \\
\hline
\end{tabular}

*annealing temperature differs with primers.

Table.2 Two List of the primers

\begin{tabular}{|c|c|c|c|c|c|}
\hline $\begin{array}{c}\text { Marker } \\
\text { name }\end{array}$ & Forward primer (5' to $\left.3^{\prime}\right)$ & bases & Reverse primer (5' to $3^{\prime}$ ) & bases & $\begin{array}{c}\text { Annealing } \\
\text { Temp } \\
\left({ }^{0} \mathrm{C}\right)\end{array}$ \\
\hline NLGS368 & TCTТCСТАТТАТТССАСТССАТСС & 24 & ACCAACTGCAGGTGTGTTGA & 20 & 53 \\
\hline BM85 & ACGGTGTACAAGAAGCTGAA & 20 & ATAACGGATTTTGGTTTGGT & 20 & 52 \\
\hline BM75 & TCACGTTTATTCCATCATCC & 20 & AAGTTGGAAAGGCAGTTAGG & 20 & 54 \\
\hline BM263 & GCCTTAGTCGTATCAGCAAA & 20 & TTGCAGCTTGAGTAGTCACC & 20 & 52 \\
\hline NLGS1680 & AGCCAACAACAAACAGGGAC & 20 & CTTCCAGCAGACAGGTCACA & 20 & 53 \\
\hline NLGS2120 & AGGAAGGAACTGAACTGGCA & 20 & GCTCACTCTCCTGCTCCATC & 20 & 54 \\
\hline NLGS928 & TCATТСТСТАТТТТСССТСССА & 22 & GCAAGGATTGATAAGACGCA & 20 & 55 \\
\hline NLGS872 & TCGTATGATCAGCGGATTGA & 20 & CCCAATTTCAACAAAGGGAA & 20 & 53 \\
\hline NLGS1016 & ATTTTGCATCCAGGTGCTTC & 20 & GGAAAACTCGCTGACGACAT & 20 & 52 \\
\hline NLGS231 & CAAGGAGAAGAAGAACAAGGGA & 22 & AAGGAGGGTGTAGCAGAGAGTG & 22 & 52 \\
\hline
\end{tabular}


Table.3 Number of alleles, highest frequency allele and polymorphism information content (PIC) Values found among 25 Brown plant hoppers for 10 SSR markers

\begin{tabular}{|l|c|c|c|c|c|l|}
\hline Marker & $\begin{array}{l}\text { Linkage } \\
\text { Group }\end{array}$ & $\begin{array}{l}\text { Allele } \\
\text { number }\end{array}$ & $\begin{array}{l}\text { Amplicon size } \\
\text { range (bp) }\end{array}$ & $\begin{array}{l}\text { Major allele } \\
\text { frequency }\end{array}$ & $\begin{array}{l}\text { Gene } \\
\text { diversity }\end{array}$ & PIC \\
\hline NLGS368 & 1 & 7 & $150-175$ & 0.5385 & 0.4970 & 0.3745 \\
\hline BM85 & 2 & 5 & $150-165$ & 0.6154 & 0.4734 & 0.3613 \\
\hline BM75 & 3 & 5 & $150-180$ & 0.6308 & 0.4658 & 0.3573 \\
\hline BM263 & 4 & 7 & $130-150$ & 0.5231 & 0.4989 & 0.3745 \\
\hline NLGS1680 & 5 & 5 & $150-164$ & 0.6923 & 0.4260 & 0.3353 \\
\hline NLGS2120 & 6 & 6 & $150-167$ & 0.5385 & 0.4970 & 0.3735 \\
\hline NLGS928 & 7 & 6 & $200-253$ & 0.5692 & 0.4904 & 0.3702 \\
\hline NLGS872 & 8 & 7 & $134-150$ & 0.6000 & 0.4800 & 0.3648 \\
\hline NLGS1016 & 9 & 5 & $130-154$ & 0.6000 & 0.4800 & 0.3648 \\
\hline NLGS231 & 10 & 6 & $130-167$ & 0.5231 & 0.4989 & 0.3745 \\
\hline MEAN & & $\mathbf{5 . 9 0}$ & & $\mathbf{0 . 5 8}$ & $\mathbf{0 . 4 8}$ & $\mathbf{0 . 3 7}$ \\
\hline
\end{tabular}

Table.4 Grouping of BPH on based on molecular diversity using SSR markers

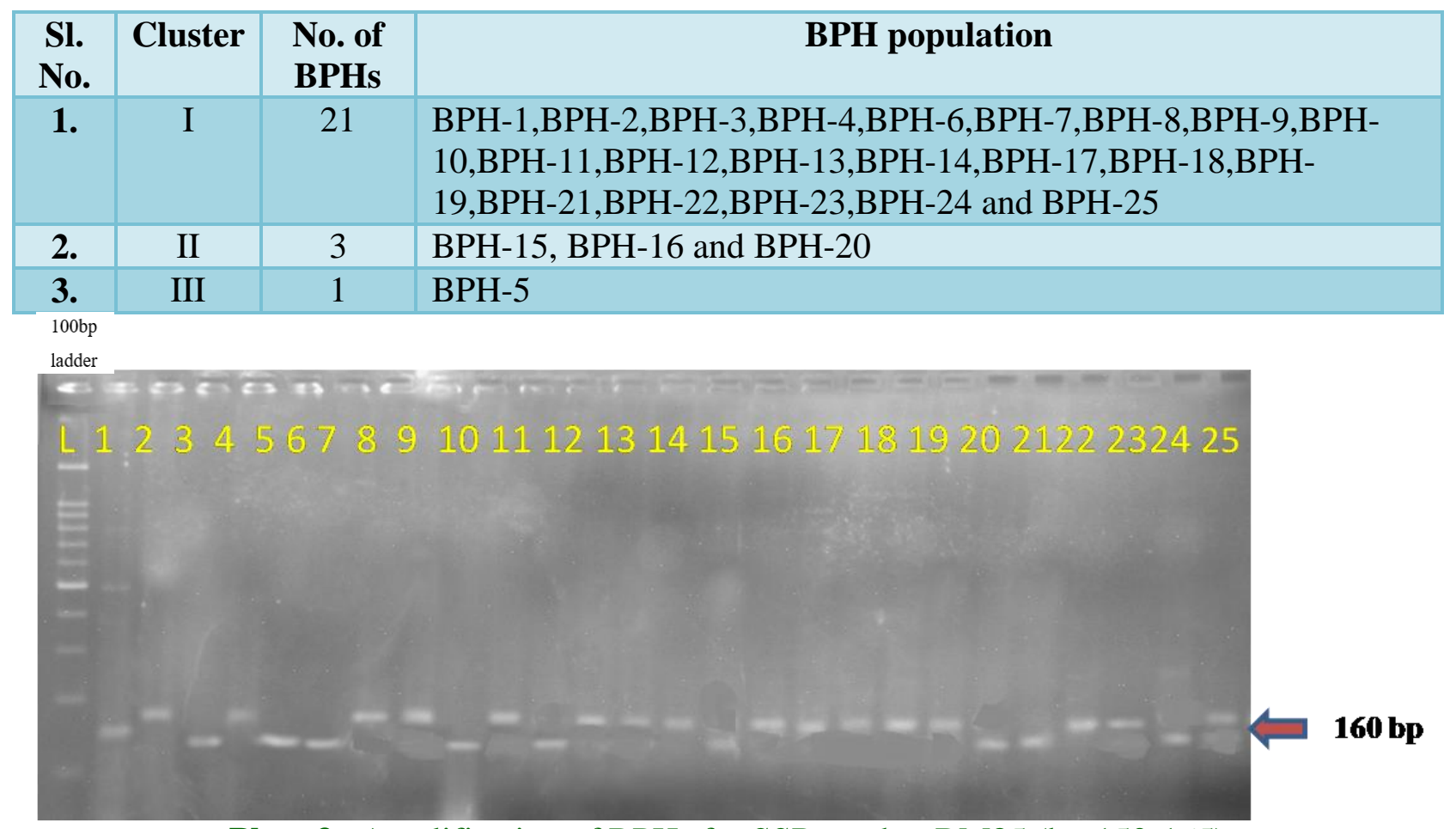

Plate.3a Amplification of BPHs for SSR marker BM85 (bp-150-165) 

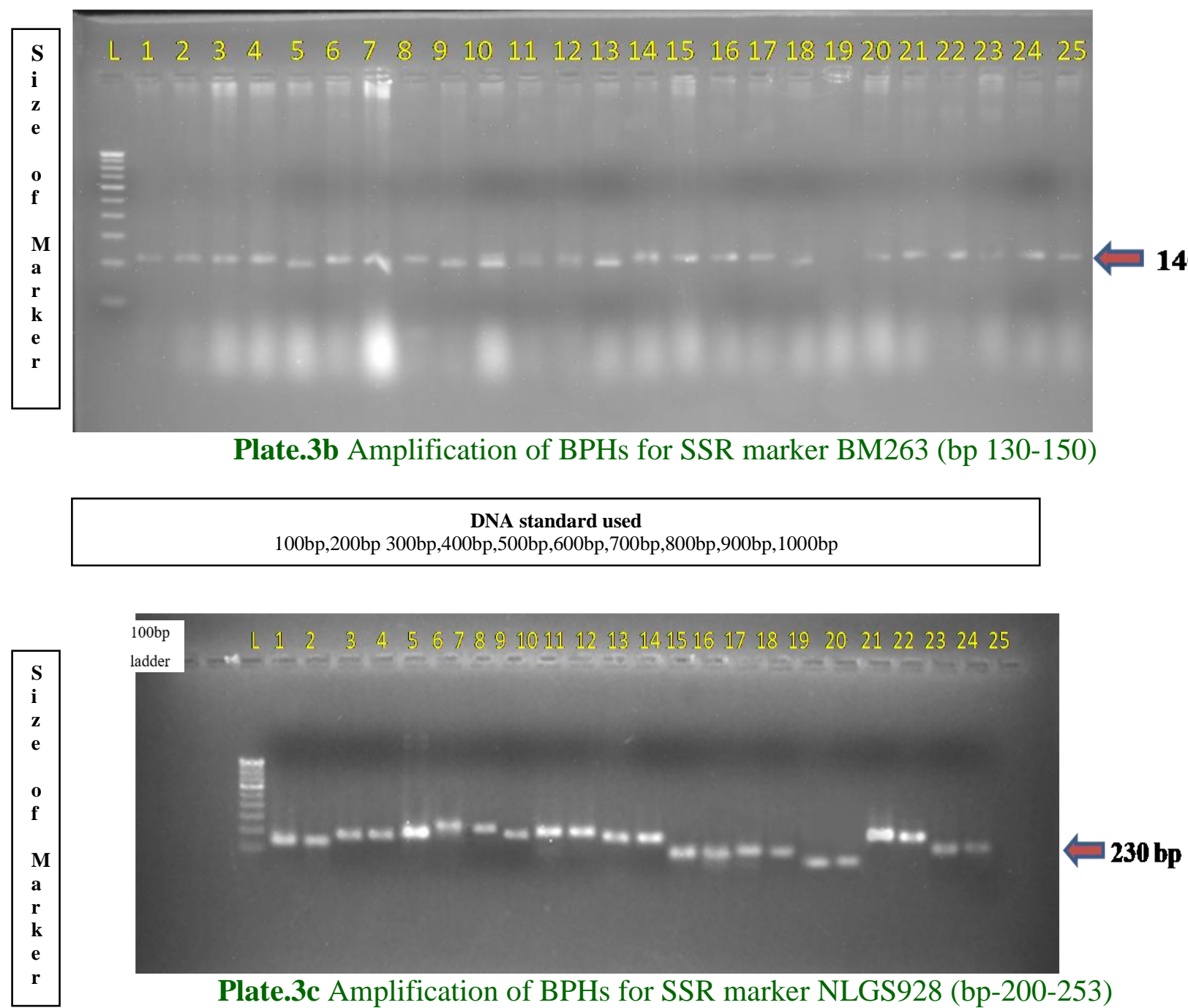

DNA standard used

100bp,200bp 300bp,400bp,500bp,600bp,700bp,800bp,900bp,1000bp

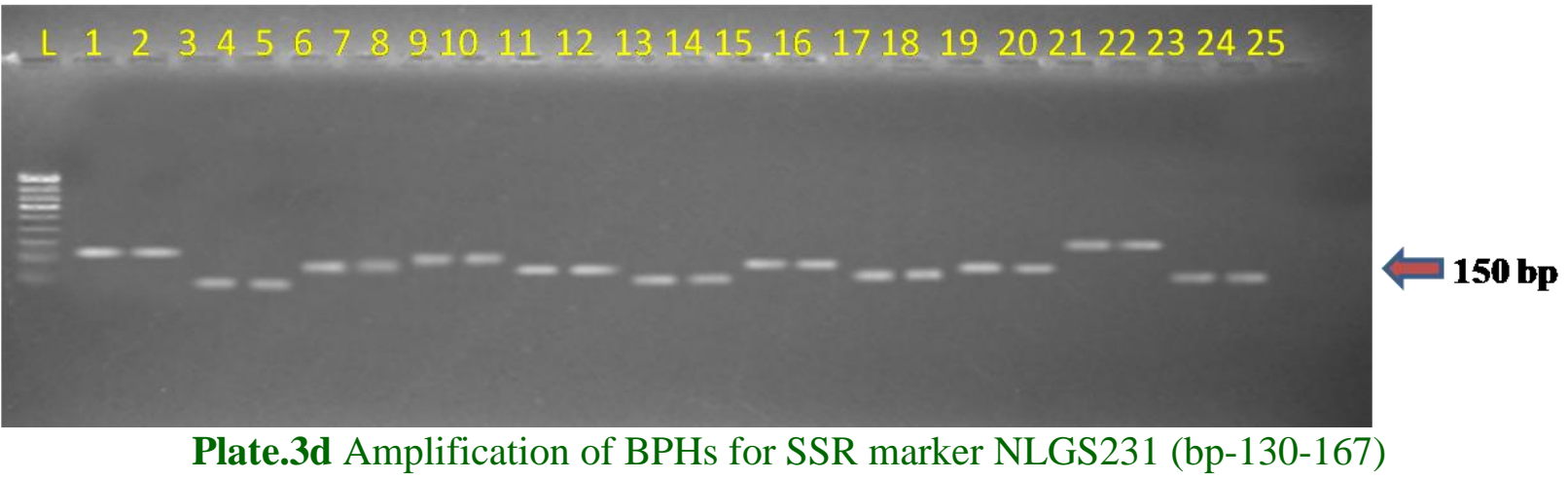

DNA standard used

100bp,200bp 300bp,400bp,500bp,600bp,700bp,800bp,900bp,1000bp 
Ten SSR markers were screened in the selected 25 BPHs and all ten markers were screened to assess the molecular diversity.Genotyping data of SSR markers were analyzed using Unweight pair group method with Arithmetic Mean (UPGMA) method using DARwin V6.0. This analysis clustered $25 \mathrm{BPH}$ populations into three groups. Cluster-I had highest number of genotypes possessing 21 genotypes. Cluster-II with three genotypes and cluster-III had solitary genotype. This indicates that majority of the BPH populations are similar at Gangavathi whereas two biotypes are quite different.

Matin et al., 2012, Wunna et al., (2016), Okoshi et al., (2016), Samal et al., (2014) and Krupa et al., (2017) observed similar kind of variation for Polymorphism Information Content (PIC) value and gene diversity in their experiments and these results are on par with the present investigation

\section{References}

Anderson, J. A., Churchill, G. A., Sutrique, J. E., Tanksley, S. D. and Sorrells, M. E., 1993, Optimizing Parental Selection for Genetic Linkage Maps. Genome, 36:181-186.

Krupa, K. N., Shashidhar, H. E., Ningaraj Dalawai, Mahendra Reddy and Vijaykumara Swamy, H. V., 2017, Molecular Marker Based Genetic Diversity Analysis in Rice Genotypes (Oryza sativa L.) Using SSR Markers. Int. J. Pure App. Biosci., 5(2): 668-674. Matin, S., Ashrafuzzaman, M., Islamil, M.
M., Sikdar, S. U. and Zobayer, N, 2012, Molecular Marker Based (SSR) Genetic Diversity Analysis in Deep Water Rice Germplasms of Bangladesh. International Journal of Biosciences, 10(2): 64-72.

Mun, J. H., Song, Y. H., Heong, K. L. and Roderick, G. K., 2007, Genetic Variation Among Asian Populations of Rice Plant Hoppers, Nilaparvata Lugens and Sogatella furcifera (Hemiptera: Delphacidae): Mitochondrial DNA Sequences. Biochemical Genetics, 89(3): 245-253.

Nishanth, G. K., (2017). Studies on Submergence Tolerance Mechanism in Rice Germplasm Lines with Relation to Genetic, Molecular and Physiological Aspects, Ph. D Thesis UAHS, Shimoga.

Okoshi, M., Matsuno, K., Okuno, K., Ogawa., Itani, T. and Fujimura, T., 2016, Genetic Diversity in Japanese Aromatic Rice (Oryza sativa L.) as Revealed by Nuclear and Organelle DNA Markers. Genetic Resources and Crop Evolution, 63(2): 199-208.

Samal, K. C., Meti, N., Bastia, D. N. and Rout, G. R., 2014, Genetic Diversity Analysis of Traditional Aromatic Rice Using Molecular Markers. Bio. Med. Research., 1(1): 1-14.

Shilpakala, Jhansi Lakshmi, V., Seshumadhav, M., Venkateswarlu, N. C., Gururajkatti, G. Padmavathi, (2012), Molecular Characterisation of Rice Brown Planthopper BPH, Nilaparvata Lugens (Stal) Populations of India. International Rice Research Conference.

\section{How to cite this article:}

Farzana Korabu, B. Kisan, I. Shanker Goud, Ayyangowda Patil, Mahantesh Shivyoggaya and Sujay Hurali. 2020. Molecular Characterisation of DNA of Brown Plant Hopper Biotypes (Nilaparvata lugens L.) Under Screening Study of Brown Plant Hopper Resistance in Various Rice Genotypes at Gangavathi. Int.J.Curr.Microbiol.App.Sci. 9(07): 2358-2364. doi: https://doi.org/10.20546/ijcmas.2020.907.275 